\title{
Improvement of Pneumonia in a Patient with Non-Small Cell Lung Cancer Treated with Herbal Medicine after Cessation of Antibiotics - a Case Report
}

\author{
Si Yeon Song', Hyeonjin Jeon ${ }^{1}$, Sookyung Lee ${ }^{2}$ \\ ${ }^{1}$ Department of Clinical Korean Medicine, Graduate School, Kyung Hee University \\ ${ }^{2}$ Cancer Center, Kyung Hee University Hospital at Gangdong, College of Korean Medicine, Kyung Hee University
}

A 73-year-old non-small cell lung cancer (NSCLC) patient admitted due to cough, sputum, and dyspnea, aggravated a week ago. She was diagnosed as pneumonia based on the assessment of inflammation markers, chest X-ray and sputum culture. Computed tomography (CT) scan was conducted to exclude malignant tumor metastasis. At the initiation of treatment, considering underlying disease and inflammation marker level, herbal medicine and antibiotics were concurrently used and antibiotics had been discontinued after 10days. Using the monotherapy of herbal medicine in the next 6 days, chest X-ray showed remarkably decreased infiltration in right middle lung and right lower lung. This case represented additional improvement of chest X-ray when treated only with herb medicine after termination of antibiotic therapy and demonstrated the possibility of applying herbal medicine in patients with limited use of antibiotics.

$\overline{\text { Key Words }}$ : Non-Small Cell Lung Cancer, Pneumonia, Antibiotic, Herbal Medicine

\section{Introduction}

Pulmonary infections such as pneumonia frequently occur in patients with lung cancer and most are pessimistic on survival. ${ }^{1)}$ Pneumonia was the main or accessory cause of death in $58.5 \%$ patients who died of lung cancer. ${ }^{2)}$

The diagnosis of pneumonia is established on the clinical symptoms such as cough, fever, sputum, high white blood cell count (WBC) and it is supported usually by chest radiography. The respiratory symptoms of pneumonitis, including cough, shortness of breath, and purulent sputum, overlap with the expressions of lung cancer. In some lung cancer patients the local bronchial developments may lead to obstructive pneumonia." ${ }^{3)}$ Therefore early identification of pneumonia is challenging specifically among non-small cell lung cancer (NSCLC) patients. It is necessary to encourage immediate diagnosis and appropriate treatment of pneumonia in NSCLC patients to prevent potential detrimental event. CT scan and sputum culture test could be taken to identify whether pneumonia is caused by tumor or infection.

In terms of treatment for pneumonia, western medicine relies on empirical antibiotic therapy. The empirical treatment is recommended due to the limited accessibility of microbiological tests and the

\footnotetext{
- Received : 1 June 2017 - Revised : 9 June $2017 \quad$ Accepted : 16 June 2017

- Correspondence to : Sookyung Lee

Cancer Center, Kyung Hee University Medical Center at Gang-dong

892 Dongnam-ro, Gangdong-gu, Seoul, 05278, South Korea

Tel : +82-2-440-6229, Fax : +82-2-440-6229, E-mail : sookyung@khu.ac.kr
} 
possibility of rapid outcomes of infection in lung cancer patients. ${ }^{4}$

In Korean medicine, infectious disease is treated by herbal medicine from the past and several herbal medications are used for pneumonia. A number of articles presented effective medical resolutions of pneumonia patients with Korean medicine., ${ }^{5,6)}$ There were also some reports on managing pneumonia in lung cancer patients. ${ }^{7,89)}$ Herein, we report one old patient with NSCLC who suffered pneumonia with recurrent improvement and worsening and showed additional advance using herbal medication after finishing antibiotics.

\section{Case Presentation}

A 73-year-old woman had been diagnosed as NSCLC in left upper lobe with mediastinum and pericardial invasion (lymphoepithelioma-like cancer (LELC), clinical stage of T4N3Mx) on July 2009. After the diagnosis, she received pericardiocentesis, allergen removed Rhus verniciflua strokes extracts, gemicitabine plus cisplantin regimen chemotherapy and several radiotherapies to chest. Gefitinib was administered for second regimen from 2010 to 2013, but tumor was progressed and she received surgery to remove mass in bronchus by bronchoscopy three times in between. Pemetrexed monotherapy was administered from 2013 to 2016 but it discontinued because of worsening general weakness. Now her left lung is totally collapsed due to endobronchial obstructing lesion in left main bronchus (Fig. 1). Therefore she has coughs and mild dyspnea usually and took codeine. She also has history of repetitive pneumonia which of the latest incident took place in December 2016.

The patient was referred to our hospital because of cough, sputum and dyspnea on March 2017. At admission, she presented continuous cough, dark yellowish phlegm, severe shortness of breath after activity, wheezing, reddish cheek and poor

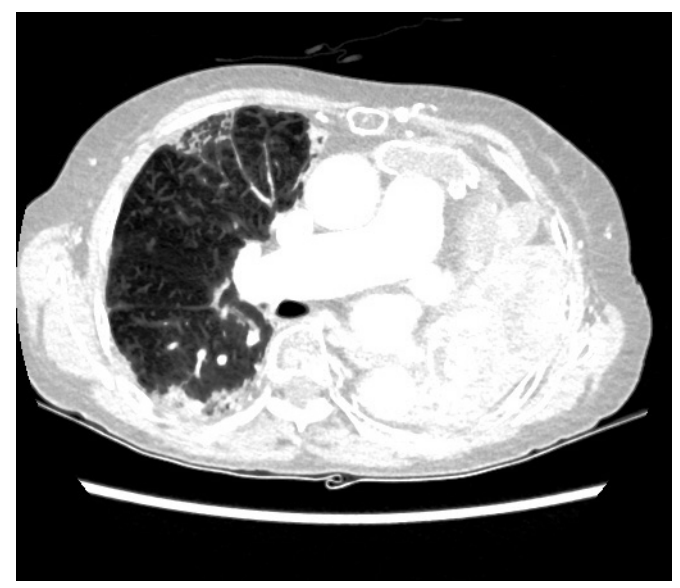

Fig. 1. Chest CT image.

Chest CT scan demonstrated endobronchial obstructing lesion in distal main bronchus, increased extent and totally replaced left lung.

performance status of Eastern Cooperative Oncology Group Performance Status (ECOG-PS) 3. Her vital signs were displayed within normal rage without any signs of fever.

Among the laboratory findings, the inflammation markers, including WBC, neutrophil counts, Erythrocyte sedimentation rate (ESR), C-reactive protein (CRP) and procalcitonin were elevated (Table. 1). The chest $\mathrm{X}$-ray presented peribronchial increased opacity in right lung (Fig. 2). Pseudomonas aeruginosa were found in sputum culture. We diagnosed the patient as bronchopneumonia.

As a result of being LELC patient, general condition was poor and the function of her left lung had been deprived. In the event of a decreased function of the right lung, the rapid progression of pneumonia could cause a fatal situation. Considering underlying disease and level of inflammation markers, empirical antibiotics, piperacillin/tazobactam, was administered along with the Korean medicine. Gami shigyungbanha-tang which is widely used treatment for pneumonia in Korean medicine was administered four times a day.

The day after administration, the patient showed 


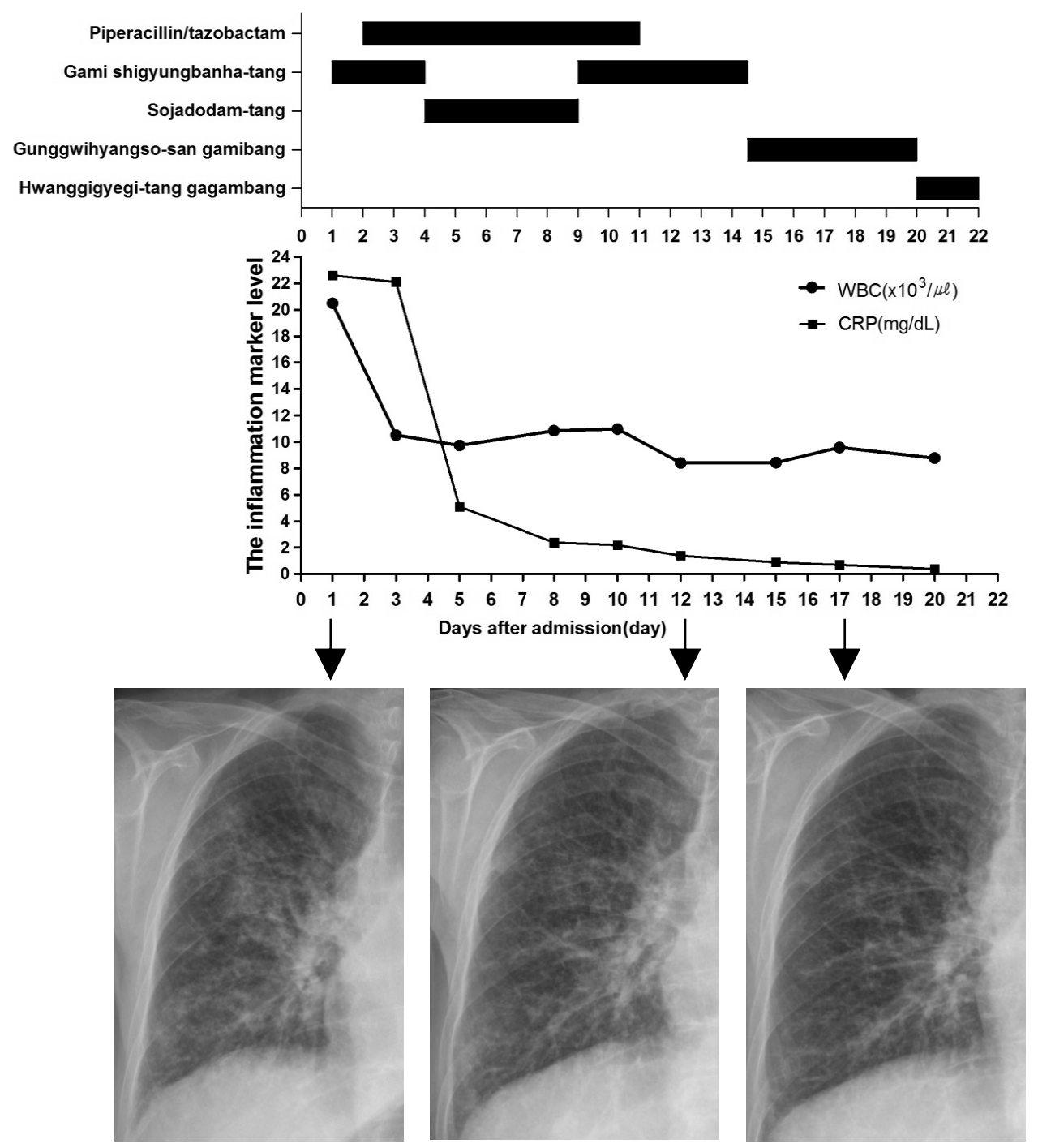

Fig. 2. The change of laboratory and radiological outcomes of patient though progress of treatment.

The Inflammation marker level, White Blood Cell Count (WBC), C-reactive protein (CRP), decreased with progression of treatment and chest X-ray represented infiltration change of right lung on day 1, day 12, day17 (arrows).

deterioration of clinical signs and her chest X-ray indicated progression of pneumonia. However, on the third day, not only the intensity and frequency of cough but also noticeable amount of sputum decreased. Moreover, inflammation marker level and opacity in the radiographic image declined (Table. 1, Fig. 2). Therefore, sojadodam-tang was administered in regard to change of the patient's symptoms, and the symptoms continuously abated for following five days.

However, on the eighth day, the patient manifested extended cough over the night after long conversation with guests in a lounge. The inflammation marker levels rose and the chest X-ray did not improve, so 
Table. 1. The Progress of Inflammation Markers

\begin{tabular}{lccccccccc}
\hline & Day1 & Day3 & Day5 & Day8 & Day10 & Day12 & Day15 & Day17 & Day20 \\
\hline $\mathrm{WBC}^{*}\left(\times 10^{3} / \mu \mathrm{l}\right)$ & 20500 & 10520 & 9730 & 10850 & 10980 & 8410 & 8440 & 9590 & 8770 \\
\hline Neutrophil segment $(\%)$ & 89.0 & 80.7 & 74.6 & 76.8 & 76.3 & 68.1 & 73.6 & 67.4 & 58.2 \\
\hline $\mathrm{ESR}(\mathrm{mm} / \mathrm{h})^{\dagger}$ & 108 & $>120$ & $>120$ & $>120$ & $>120$ & 110 & $>120$ & 109 & $>120$ \\
\hline $\mathrm{CRP}(\mathrm{mg} / \mathrm{dL})^{\dagger}$ & 22.6 & 22.1 & 5.1 & 2.4 & 2.2 & 1.4 & 0.9 & 0.7 & 0.4 \\
\hline Procalcitonin $(\mathrm{ng} / \mathrm{mL})$ & 0.075 & 0.082 & 0.039 & 0.055 & 0.068 & 0.049 & 0.062 & 0.066 & 0.060 \\
\hline
\end{tabular}

${ }^{*}$ White Blood Cell Count (WBC). ${ }^{\dagger}$ Erythrocyte sedimentation rate (ESR). ${ }^{\dagger}$ C-reactive protein (CRP).

Table. 2. Prescriptions of Administered Herbal Medicine

\begin{tabular}{|c|c|c|c|}
\hline \multirow{2}{*}{ Prescription Name } & \multirow{2}{*}{ Main Ingredients (gr per day) } & \multicolumn{2}{|c|}{ Adjusted Ingredients (gr per day) } \\
\hline & & Included & Excluded \\
\hline $\begin{array}{c}\text { Gami } \\
\text { shigyungbanha-tan } \\
g\end{array}$ & 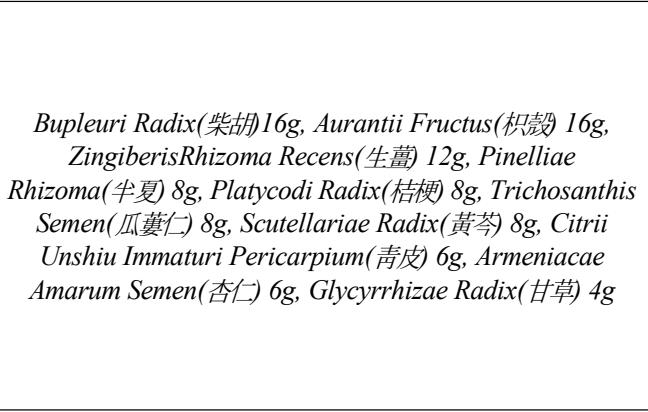 & 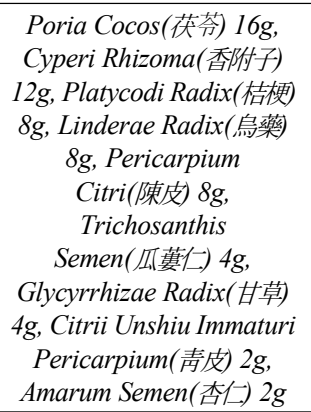 & \\
\hline Sojadodam-tang & $\begin{array}{c}\text { Perillae Fructus(蘇子) } 16 g \text {, Pinelliae Rhizoma(牛夏) } 12 g, \\
\text { Zizyphi Fruxtus(大柬) } 12 g \text {, Angelicae Gigantis Radix(當歸) } \\
12 g \text {, Zingiberis Rhizoma Recens(生䓒) } 12 g \text {, Pericarpium } \\
\text { Citri(陳皮) } 8 g \text {, Arisaematis Rhizoma(南星) } 8 g \text {, Magnoliae } \\
\text { Cortex(厚朴) 6g, Aurantii Immaturus Fructus(枳實) } 6 g, \\
\text { Glycyrrhizae Radix(甘草) } 4 g\end{array}$ & $\begin{array}{l}\text { Perillae Folium(蘇葉) } 8 g, \\
\text { Perillae Fructus(蘇子) } 4 g\end{array}$ & \\
\hline $\begin{array}{l}\text { Gunggwihyangso-s } \\
\text { an gamibang* }\end{array}$ & 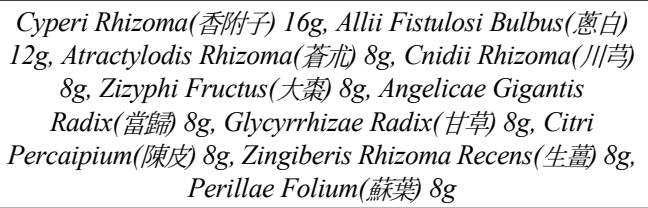 & $\begin{array}{l}\text { Cinnamomum Cassia } \\
\text { Blume(桂枝) } 24 g, \\
\text { Paeoniae Radix(茑藥) } 16 g, \\
\text { Perillae Fructus(蘇子) } 8 g, \\
\text { Perillae Folium(蘇葉) } 4 g\end{array}$ & \\
\hline $\begin{array}{l}\text { Gunggwihyangso-s } \\
\text { an gamibang }+\end{array}$ & 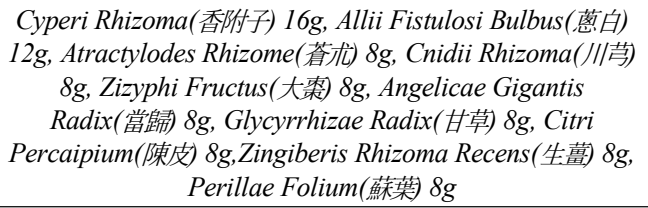 & $\begin{array}{l}\text { Perillae Fructus(蘇子) } 8 g, \\
\text { Perillae Folium(蘇葉) } 4 g\end{array}$ & \\
\hline $\begin{array}{l}\text { Hwanggigyegi-tang } \\
\text { gagambang }\end{array}$ & 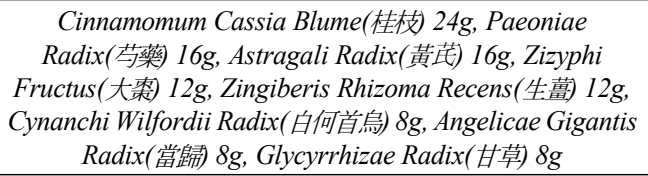 & $\begin{array}{l}\text { Perillae Folium(蘇葉) } 12 g, \\
\text { Astragali Radix(黄烒) } 8 g, \\
\text { Perillae Fructus(蘇子) } 8 g\end{array}$ & $\begin{array}{c}\text { Cinnamomum } \\
\text { Cassia } \\
\text { Blume(桂枝) } 8 g\end{array}$ \\
\hline
\end{tabular}

gami shigyungbanha-tang was re-administered. On day 11 , although the patient's symptoms remained the same, antibiotics were stopped because inflammation markers and opacity in chest X-ray had 
decreased in general.

On day 14, cough, sputum was aggravated and rhinorrhea, mild sweating and heat sensation newly appeared. Gunggwihayngso-san gamibang was used to alleviate emerging symptoms. Significant improvement appeared on follow up chest X-ray (Fig. 2) and cough, sputum and rhinorrhea declined. But heat sensation with sweating still occurred six times a day. We assumed this might be due to high dose of Cinnamomum cassia Blume in Gunggwihaynso-san gamibang, thus the amount of Cinnamomum cassia Blume was reduced. The next day, heat sensation and sweating lessened to one or twice a day. Because of mild sweating and general weakness, Hwanggigyegi-tang gagambang was administered for management of both pneumonia and overall condition.

She was discharged on day 22 after abatement in symptoms such as cough, sputum and dyspnea. There was no remarkable change in follow up chest X-ray and laboratory test performed one week after discharge. However, general condition along with cough, sputum and sweating were better.

\section{Discussion}

The outcome of this case demonstrated successful management of pneumonia in elderly patient with NSCLC. The patient's clinical features, laboratory and radiological assessments correlated with signs and symptoms of pneumonia. Typically, pneumonia increase mortality in elderly who suffer from multiple chronic diseases. ${ }^{10)}$ Malignant tumor carries a high risk of fatal respiratory failure so it should be treated with extra care.

Because she was a NSCLC patient and had a history of repetitive pneumonia, she also had a possibility of obstructive pneumonia by cancer mass of the lung. Chest CT scan was conducted to evaluate whether pneumonia was induced by an obstructed bronchus. Compared with previous chest CT on April 2016, endobronchial obstructing lesion in distal main bronchus increased its extent and left lung had totally collapsed. Increased infiltration in right middle lobe and right lower lobe was identified. However, metastasis to the right lobe was excluded thus we treated her focusing on respiratory inflammation.

In a western medicine, a successful therapy of pneumonia requires appropriate empirical remedies. Combination empirical therapy for severe pneumonia is strongly recommended by increasing evidence. ${ }^{11)}$ The optimal total duration of antibiotic usage for pneumonia has not been defined in prospective studies, however, in a regular procedure, 10-14 days is the usual duration of therapy. ${ }^{12)}$ In this case, the patient's pneumonia was treated with piperacillin/ tazobactam along with herbal medicine because inflammation markers appeared to be alarmingly high to be treated only with herbal medication.

After 10days of administration, cessation of antibiotics was suggested by infectious disease internists in accordance with overall clinical signs and inflammation levels which appeared to have reduced to certain degree. Moreover, the patient had diarrhea, from the beginning to termination of antibiotics, causing trouble in sleeping and deteriorating general weakness which could delay the recovery. We were careful about persistent use of antibiotics because extra transition of inflammation markers or opacity in chest X-ray was not observed also, it could rather raise risk of resistance to antibiotics, resulting from cumulative dose effect. Therefore, antibiotic therapy was terminated and we preceded medical treatment with herbal medicine alone.

On the day of administration, gami shigyungbanha -tang was used to treat pneumonia. Shigyungbanha-tang is a prescription from Uihagimmun which has long been used to treat the activated phlegm-heat induced fever, cough, chest fullness and flank pain. ${ }^{13)}$ It has been reported that shigyungbanha-tang has positive response in an elderly patient diagnosed with 
pneumonia $^{5)}$ and anti-inflammatory effects by inhibiting $\mathrm{I} \kappa \mathrm{B}-\mathrm{a}$ degradation in LPS-stimulated peritoneal macrophages in rats. ${ }^{14)}$ Although shortness of breath lessened considerably, the relieving signs of cough and sputum fluctuated.

Subsequently targeting on her difficulty to expectorate phlegm, Sojadodam-tang was adopted because the patient was considered as Soeum person by Sasang Constitutional Medicine. However, on the eighth day, her symptoms were aggravated and inflammation markers and chest X-ray infiltration increased, so we re-administered Gami shigyungbanha-tang to take precautions against regression of pneumonia (Table. 1, Fig. 2).

On day 14, the patient started to exhibit deteriorated cough, sputum with newly developed rhinorrhea, mild sweating, and heat sensation. We diagnosed her as having comorbid common cold. Herbal medicine was changed to gunggwihyangso -san gamibang to alleviate exterior symptoms of early-stage of acute infectious disease. Interestingly, laboratory examination and chest X-ray follow-up noticeably improved compared to minor changes on previous X-ray. By day 17, the infiltration on right lung decreased even more. These findings suggest gunggwihyangso-san gamibang could have been more effective in initial pneumonia treatment than piperacillin/tazobactam and gami shigyungbanha-tang.

On the other hand, the sweating and heat sensation continued, hence the dosage of Cinnamomum cassia Blume in Gunggwihaynso-san gamibang was reduced from $24 \mathrm{~g}$ per day to none (Table. 2). Cinnamomum cassia Blume is known for Balhanhaegi, Ongyeongtongmaek, Joyanghwagi. ${ }^{15)}$ Efficacy in bringing sweating, removing the stagnated pathogenic Gi in muscles, making congested regular meridians flow well and helping Yang energy and firing Gi. The intensity and frequency of sweating and heat sensation gradually subsided.

The immediate improvement of pneumonia after termination of antibiotics and administration of gunggwihaynso-san gamibang strongly prove the therapeutic potential of herbal treatment. However, there is a limitation to claim the effect of herbal medicine on pneumonia of lung cancer. Even if the positive response of herb medicine is certain, the possibility of late reaction of pneumonia after withdrawal of antibiotics cannot be ruled out completely. In addition, it was difficult to evaluate the effect of a single herbal medicine for prescriptions were altered continuously as symptoms varied through progression of treatment.

In conclusion, we report a successfully managed pneumonia of advanced lung cancer patient. The clinical outcomes, chest X-ray and inflammation markers showed transient deteriorations and overall improvements using herbal medicine with antibiotics. A therapeutic benefit of herbal medicine was implied by additional improvement demonstrated in chest X-ray after termination of antibiotic therapy in patients with restricted use of antibiotics.

\section{References}

1. Perlin E, Bang KM, Shah A, Hursey PD, Whittingham WL, Hashmi K, et al. The impact of pulmonary infections on the survival of lung cancer patients. Cancer. 1990;66(3):593-6.

2. Zięba M, Baranowska A, Krawczyk M, Noweta K, Grzelewska-Rzymowska I, Kwiatkowska S. Pneumonia as a cause of death in patients with lung cancer. Radiol Oncol. 2003;37(3):167-74.

3. Syrigos K, Nutting C, Roussos C. Tumors of the Chest: Biology, Diagnosis and Management. 1st ed. NewYork:Springer Science \& Business Media. 2006:109-10.

4. Talcott JA, Siegel RD, Finberg R, Goldmann L. Risk assessment in cancer patients with fever and neutropenia: A prospective, two-centre validation of a prediction rule. J Clin Oncol. 1992;10(2):316-22.

5. Shin WY, Hyun MK, Jeong BM, Choi EY, 
Yoon $\mathrm{CH}$, Jeong JC. A clinical report of one old aged patient with pneumonia. Korean J Orient Int Med. 2005;26(1):229-35.

6. Kang JY, Han JM, Kim JY, Jung IC, Kang WC, $\mathrm{Oh}$ YS, et al. Management of idiopathic interstitial pneumonia treated only with traditional korean medicine: a case report. J Korean Med. 2014;35(4):104-9.

7. Cha ES, Jo IH, Lee GG, Jo YM, Jeong HJ, Jeong SG, et al. A case of postobstructive pneumonia in lung cancer patient by oriental medical. J of Korean Oriental Oncology. 1997;3(1):207-19.

8. Chae J, Lee JY, Song A, Choi SH, Lee SM, Jung $\mathrm{YH}$, et al. Effect of saengmaek-san on cancer patients with symptoms related to radiation pneumonitis after radiotherapy : report of 2 cases. $\mathrm{J}$ of Kor Traditional Oncology. 2013;18(1):1-7.

9. Zhang T, Ma SL, Yue JH. Clinical observation on treatment of radiation pneumonia by Qingjin Runfei Decoction combined with hormone and antibiotic.Zhongguo Zhong xi yi jie he za zhi. 2007;27(3):254-6.
10. Welte T, Torres A, Nathwani D. Clinical and economic burden of community-acquired pneumonia among adults in Europe. Thorax. 2012;67(1):71-9.

11. Mandell LA, Wunderink RG, Anzueto A, Bartlett JG, Campbell GD, Dean NC, et al. Infectious Diseases Society of America/American Thoracic Society consensus guidelines on the management of community-acquired pneumonia in adults. Clin Infect Dis. 2007;44 Suppl 2:S27-72.

12. Marrie TJ. Community-acquired pneumonia in the elderly. Clin Infect Dis. 2000;31(4):1066-78.

13. Hwang DY. Bangyakhappyeon. Seoul:HangLim. 1993:173.

14. Lee SE, Shin JY, Lee SH. Shigyungbanha-tang Exhibits Anti-inflammatory Effects by Inhibiting I $\kappa \mathrm{B}-a$ Degradation in LPS-stimulated Peritoneal Macrophages. Korean J Orient Int Med. 2007; 28(3):442-52.

15. University of Korean medicine editorial committee of bonchohak. Bonchohak. 2nd ed. Seoul: Yeongnimsa. 2010:154-5. 